Article

\title{
Epidemiology of Traumatic Tusk Fractures of Managed Elephants in North America, South America, Europe, Asia and Australia
}

\author{
Josephine B. Rose ${ }^{1,2, *} \mathbb{C}$, Austin Leeds $\left.{ }^{3}{ }^{(}\right)$, Rachel LeMont ${ }^{4}$, Linda M. Yang ${ }^{5}$, Melissa A. Fayette ${ }^{6}$, \\ Jeffry S. Proudfoot ${ }^{6}$, Michelle R. Bowman ${ }^{6}$, Allison Woody ${ }^{7}$, James Oosterhuis ${ }^{7}$ and David A. Fagan ${ }^{7}$
}

\section{check for}

updates

Citation: Rose, J.B.; Leeds, A.;

LeMont, R.; Yang, L.M.; Fayette,

M.A.; Proudfoot, J.S.; Bowman, M.R.; Woody, A.; Oosterhuis, J.; Fagan, D.A Epidemiology of Traumatic Tusk Fractures of Managed Elephants in North America, South America, Europe, Asia and Australia. J. Zool. Bot. Gard. 2022, 3, 89-101. https:// doi.org/10.3390/jzbg3010008

Academic Editor: Steven Monfort

Received: 12 January 2022

Accepted: 28 February 2022

Published: 3 March 2022

Publisher's Note: MDPI stays neutra with regard to jurisdictional claims in published maps and institutional affiliations.

Copyright: (C) 2022 by the authors. Licensee MDPI, Basel, Switzerland. This article is an open access article distributed under the terms and conditions of the Creative Commons Attribution (CC BY) license (https:// creativecommons.org/licenses/by/ $4.0 /)$

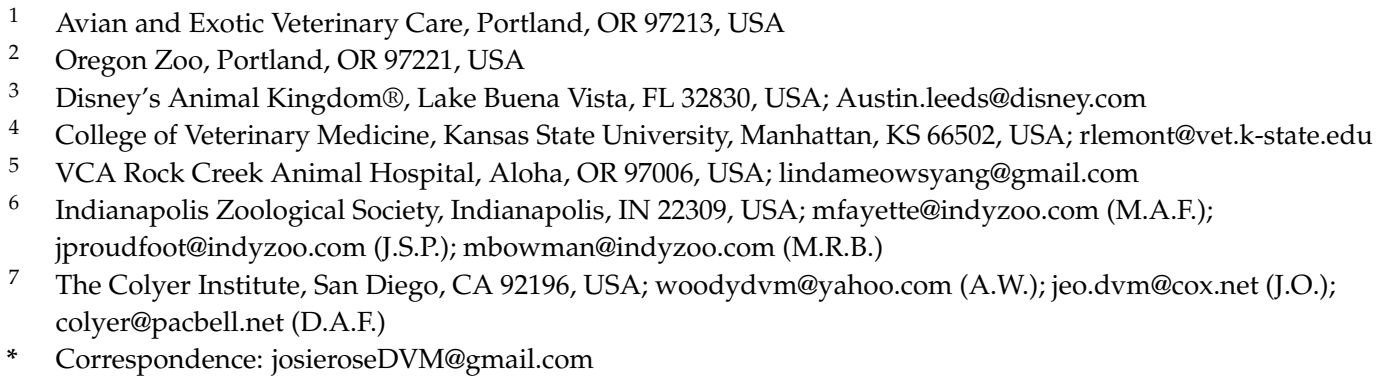

\begin{abstract}
Elephant tusk fractures are a management and medical challenge that can escalate into life-threatening complications. Here, an international survey was sent to elephant managers to understand the risk factors associated with tusk fractures since 2009, identifying best practices for reducing the incidence. Out of 459 elephants included in the survey, 85 elephants incurred at least one fracture. Though not statistically significant, descriptive statistics identified a trend for both Asian and African elephant males to be more likely to incur a fracture than females. Additionally, the first reported fracture occurred in males of both species approximately ten years earlier in age than females. The most common causes of fractures were conspecific interactions $(44.6 \%)$, caught tusk in an enclosure or enrichment item $(28.4 \%)$, and a strike by the elephant of a tusk with an object $(12.2 \%)$. For social causes, unstable hierarchy $(45.5 \%)$ and specific agonistic interactions (36.4\%) were the most frequently cited fracture causes. Steel gates were associated with $23.8 \%$ of fractures caused by enclosure elements. Management changes including tusk trimming, enrichment, training, and re-arranging social groups were found to be important in reducing subsequent fractures, with odds ratios showing that a second tusk fracture was 6.37 times more likely to occur if no management changes occurred after the first fracture. Our data suggests that targeted management strategies in herds with maturing males, unstable social dynamics, and/or high-risk enclosure elements could reduce the frequency of tusk fractures.
\end{abstract}

Keywords: Loxodonta sp.; Elephas sp.; tusk trimming; preventative tusk care; tusk fractures

\section{Introduction}

The survival of Loxodonta and Elephas species continues to face challenges due to habitat loss, fragmentation and poaching [1,2]. Elephants under human care serve as important ambassadors to the survival of their species. However, managing the largest land mammals in the world is a multifaceted endeavor with logistical and practical considerations. A critical scientific approach has optimized elephant management recommendations in topics including exercise, musculoskeletal, metabolic, and reproductive health [3-6]. While elephants' tusks are one of their most iconic features, a similar approach has yet to occur to optimize tusk health.

Elephant tusks are continuously growing maxillary incisors composed almost entirely of dentin uniquely arranged in a checkered pattern [7-10]. Defining characteristics of these 
modified teeth include their outward extension beyond the plane of the mouth [11] and comparatively low tensile strength ex vivo [12]. These traits logically would put them at a higher risk for tusk fractures. However, Asian elephant females possess "vestigial tusks" or "tushes" [13] of a shorter length that would be predicted to be less likely to fracture. Tusk fractures, particularly those that expose the highly vascular pulp and/or damage the periodontal ligament, are a challenge that can escalate into complications like uncontrolled pulpitis, nonviable tusks, pain, and even death [13-16]. Elephants will frequently pack their open pulp canal with dirt [13]. To avoid the most serious of complications from unfolding, interventions including long-term antibiotics, analgesics, endodontic treatments and/or tusk extraction are often indicated and pursued [15,17]. Sedation and/or anesthesia are often necessary to achieve these therapies [15,17], and the risk of a life-threatening outcome is again enhanced [16]. Based on previous reports, there is an increased prevalence of tusk fractures in managed elephants (31\%) [13] compared with the median overall incidence of tusk fractures in free-ranging South African elephants (1.31\%) [18]. Though the prevalence and incidence of tusk fractures in free-ranging Asian elephants has not been specifically investigated, one report identified $7.7 \%$ of its tusked male study population (3 of 39 individuals) to possess a fractured tusk [19], a prevalence still substantially lower than that reported across managed elephant species [13]. Though specific factors that could put managed elephants at a higher risk of fracturing their tusks have been described [13,17], a comprehensive statistical analysis of risk factors has not been performed. A critical evaluation of factors associated with ex situ tusk fractures should be informative to elephant managers, ultimately guiding recommendations to minimize the incidence and prevalence of fractures.

This study surveyed an international group of institutions managing elephants to better understand the occurrence and causes of tusk fractures. Particularly, our surveys sought to (1) determine the overall fracture prevalence and incidence since 2009 and the individual elephant characteristics among those fractures, (2) determine if any existing tusk pathologies and/or endodontic treatments were present at the time of the fractures, (3) determine the circumstances directly precipitating the fractures, (4) describe the housing factors of the elephants at the time of the fractures, (5) determine whether any behavioral factors were relevant to the development of the fractures and (6) evaluate the impact that interventions have had on preventing further fractures. This study was designed as a broad approach to better understand the complexities and patterns associated with tusk fractures at the managed elephant population level, with the ultimate goal of providing recommendations that can assist institutions in minimizing the incidence of tusk fractures. Findings from this study should be informative to the care, health, and welfare of managed elephants globally.

\section{Materials and Methods}

\subsection{Sampling}

This study was endorsed by the Association of Zoos and Aquariums (AZA) Elephant Taxon Advisory Group and Species Survival Plan and the European Association of Zoos and Aquaria (EAZA) Elephant Taxon Advisory and Research Groups (Silver Spring, MD, USA). The surveys were translated from English to Japanese by Yurie Yamada, BVSc, facilitating the participation of elephant managers in the Japanese Association of Zoos and Aquariums (JAZA, Tokyo, Japan). Invitations were sent to elephant managers in North America, South America, Europe, Asia and Australia via list serves and direct email communication with known elephant managers. Each participating institution reviewed and approved our survey methodology prior to completion. Both EAZA and AZA research proposals and endorsements, including all survey questions, were provided for review via email at the time of invitation. If requested, further research approval agreements were achieved at the individual institution level. Information from the surveys was augmented with information provided through the AZA, EAZA and JAZA studbooks for both African and Asian elephants. Multiple institutions responded that no tusk fractures had occurred. 
These institutions' elephants were accounted for when calculating population incidence. The study was limited to fractures that occurred from 2009 onwards to (1) minimize record sorting/participation labor of institutions, with the goal of increasing participation and (2) to evaluate tusk fractures in relation to more contemporary elephant management practices.

\subsection{Survey}

A team of eight professionals with experience in veterinary medicine, veterinary dentistry, elephants, and multi-institutional research developed the survey to be completed by elephant managers and/or veterinarians following extensive literature review. This survey utilized an online form generator (Wufoo ${ }^{\mathrm{TM}}$ by Survey Monkey ${ }^{\circledR}$, Momentive Inc., San Mateo, CA, USA). This platform is authorized for research when the study aligns with Momentive Inc.'s terms of use [20], with which the survey complied. Six sections of questions were developed in conjunction with the six objectives of the study (File S1).

To determine the overall fracture prevalence and incidence since 2009 and the individual elephant characteristics among those fractures, the first section of the survey requested the species of elephant, stud book number, birth date of the elephant, the date the fracture occurred, the approximate weight in kilograms of the elephant at the time of the fracture, which tusk (right or left) fractured, and the approximate length of the tusk prior to fracture. Then, to determine if any existing tusk pathologies and/or endodontic treatments were present at the time of the fractures, respondents were asked to report if any of the following conditions were present in either or both the elephant's tusk(s) at the time of fracture: pericoronitis (inflammation of the soft tissue surrounding the gingival attachment of the tusk), abrasions or signs of wear on the tusk, previous tusk fracture without pulp exposure, previous tusk fracture with pulp exposure that was endodontically repaired (partial pulpotomy), previous tusk fracture with pulp exposure not endodontically repaired, tush (small vestigSial tusk in the tusk alveolus), supernumerary tusks (congenital extra tusks), metal crown/cap/circumferential reinforcement or any acrylic/Kevlar cap. A description of any molar pathology, including retained molars, twisted molars, deformed molars, fractured molars, deteriorated molars, or abnormal wear was requested as well. To determine the circumstances directly precipitating the fractures, respondents were requested to report if the following circumstances were relevant to the development of the fracture: a conspecific interaction, the tusk caught in an enclosure/enrichment item, the elephant slipping/falling/tripping, the elephant chronically wearing down the tusk and eventually exposing the pulp, unknown or other circumstance. If more than one circumstance was implicated, the respondents could 'check' multiple answers. To address the fourth goal of describing the housing factors at the time of a fracture, questions were developed to evaluate where in the enclosure the fracture occurred, the type of substrate the elephant was on at the time of fracture, the types of walls/barriers that were present in the enclosure, the manner in which feed was offered to the elephant, and the type of management (free contact versus protected contact) that the elephant was under. The survey also inquired whether any of these elements were known to be directly involved in the development of a fracture. For the fifth goal of determining relevant behavioral factors, questions were included that described the social ranking of the elephant at the time of fracture, the presence of a new elephant introduced into the herd, the presence of male(s) in behavioral musth at the time of fracture, the presence of reproductively cycling females within the herd since 2009, and whether or not social factors were directly implicated in the development of a fracture. The final goal of evaluating the impact that interventions had on preventing further fractures was accomplished by inquiring if any techniques had been implemented, including redirecting behaviors that might result in tusk fractures, adding additional enrichment items to the elephant's yard or enclosure, modifying social arrangements or the enclosure, modifying or trimming the tusks, or adding protective crowns in the absence of other tusk pathology. An opportunity to elaborate on any of these techniques was offered, in addition to space for commentary on any other variables that may have been significant in the development of a particular fracture. If one elephant 
had multiple fractures, the form was developed so that the respondent could return to the beginning of the survey and provide data for each fracture that had occurred.

\subsection{Analysis}

Data from the survey were summarized primarily with descriptive statistics, and when appropriate, inferential statistics. Data were summarized descriptively at the species/sex level, with inferential statistics applied to intraspecific sex comparisons (i.e., African female to African male; Asian female to Asian male). Distribution of data was visually examined prior to selecting statistical analysis approaches. Reflective of data distribution, nonparametric Mann Whitney U and Chi Square tests were utilized via SPSS v24 (IBM, Armonk, NY, USA). For all tests, $\alpha$ was set to 0.05 . Two counts of fractures were utilized within the subsequent analysis. The first reported fracture for an individual (with multiple fractures) was used for individual level traits (e.g., age, weight at fracture, laterality of fracture) and all fractures were used for summarizing management/incident contexts (e.g., cause of fracture, location of fracture). Both count types are noted prior to summary in results.

\section{Results}

A total of 220 institutions were contacted globally and 50 either completed the survey or reported to the authors that no tusk fractures had occurred within the study time frame, a $22.7 \%$ response rate.

\subsection{Overall Tusk Fracture Prevalence, Incidence and Individual Level Traits}

Incidence of tusk fractures were surveyed in 459 elephants living at 50 institutions (African, 76.127; Asian, 85.171; Table 1). A total of 134 tusk fractures were reported in 85 elephants (African, 20.20; Asian, 20.25). Within the study population, 18.5\% of the elephants experienced one or more tusk fractures. Fractures occurred at a rate of 11.16 per study year, with $2.4 \%$ of the study population reporting a fracture per year. Percent of study population having reported at least one fracture varied by species/sex grouping with a larger percent of males of both species experiencing a fracture (African, 26.3\%; Asian, 23.5\%) than females of both species (African, 15.7\%; Asian, 14.6\%). There was no significant difference between the frequency of fractures between male and female African elephants $\left(\chi^{2}=3.356, \mathrm{df}=1, p=0.067\right)$, though odds ratios approached a factor of two, with African males 1.92 times more likely to have a fracture than African females during the study period. There was also no significant difference between Asian males and females $\left(\chi^{2}=3.111, \mathrm{df}=1, p=0.078\right)$, with odds ratios showing males were 1.94 times more likely to incur a fracture than females during the study period.

Table 1. Tusk fracture prevalence, incidence and individual level traits within study population.

\begin{tabular}{|c|c|c|c|c|c|c|c|c|}
\hline Species & Sex & $\begin{array}{l}\text { Total } \# \text { of } \\
\text { Elephants in Study, } \\
\text { with and without } \\
\text { Fracture(s) }\end{array}$ & $\begin{array}{l}\text { Total }{ }^{\#} \text { of } \\
\text { Elephants } \\
\text { with } \\
\text { Fracture(s) }\end{array}$ & $\begin{array}{c}\text { Subset of } \\
\text { Elephants } \\
\text { with }>1 \\
\text { Fracture }\end{array}$ & $\begin{array}{c}\text { Total } \\
\text { Fractures }\end{array}$ & $\begin{array}{c}\text { Average Age } \\
\text { at First } \\
\text { Fracture (SE) }\end{array}$ & $\begin{array}{c}\text { Proportion of } \\
\text { Left/Right } \\
\text { Tusk } \\
\text { Fractures }\end{array}$ & $\begin{array}{c}\text { Average } \\
\text { Weight (kg) } \\
\text { at First } \\
\text { Fracture (SE) }\end{array}$ \\
\hline \multirow[t]{2}{*}{ African } & Female & 117 & 20 & 8 & 36 & $24.98(4.37)$ & $0.43 / 0.57$ & $2794.68(213.29)$ \\
\hline & Male & 74 & 20 & 5 & 29 & $13.86(2.59)^{1}$ & $0.55 / 0.45$ & $3247.74(422.68)$ \\
\hline \multirow[t]{2}{*}{ Asian } & Female & 120 & 25 & 10 & 41 & $26.47(3.82)$ & $0.45 / 0.55$ & 3012.89 (348.81) \\
\hline & Male & 58 & 20 & 5 & 28 & $16.37(3.77)^{1}$ & $0.53 / 0.47$ & $3420.2(569.10)$ \\
\hline
\end{tabular}

${ }^{1}$ Denotes statistically significant difference from female African and Asian elephants, respectively.

Age of first reported tusk fracture was significantly different between sexes of each species (African, $\mathrm{U}=86.500, \mathrm{z}=-2.568, p=0.009$; Asian, $\mathrm{U}=102.000, \mathrm{z}=-2.023, p=0.044$; Table 1; Figure 1). Both African $(\mu=13.86, \mathrm{Mdn}=10.17, \mathrm{SE}=2.59)$ and Asian males $(\mu=16.37, \mathrm{Mdn}=10.55, \mathrm{SE}=3.77)$ were significantly younger than African $(\mu=24.98$, $\mathrm{Mdn}=24.96, \mathrm{SE}=4.37)$ and Asian females $(\mu=26.47, \mathrm{Mdn}=20.34, \mathrm{SE}=3.82)$ at their first fracture. Weight $(\mathrm{kg})$ at first fracture did not significantly differ between sexes across species (African, $\mathrm{U}=155.000, \mathrm{z}=-0.486, p=0.641$; Asian, $\mathrm{U}=68.000, \mathrm{z}=-0.854, p=0.414$; Table 1). Laterality of fractures (left vs. right) was not associated with sex within each 
species (African, $\chi^{2}=0.551, \mathrm{df}=1, \mathrm{P}=0.458$; Asian, $\chi^{2}=0.249, \mathrm{df}=1, p=0.618$; Table 1), and generally occurred at approximately equal rates per side (Table 1 ). Tusk size prior to the first recorded fracture was not associated with sex within African elephants $\left(\chi^{2}=1.80\right.$, $\mathrm{df}=1, p=0.180$ ). Combining the sexes in African elephants, $55 \%$ of tusk fractures occurred in tusks less than or equal to $1 \mathrm{ft}$ in length, and the other $45 \%$ occurred in tusks greater than $1 \mathrm{ft}$ in length. In Asian elephants, tusk size prior to first fracture was significantly associated with sex $\left(\chi^{2}=4.740, \mathrm{df}=1, p=0.029\right)$. For females, $100 \%$ of fractures occurred in tusks less than or equal to $1 \mathrm{ft}$ in size. For males, $75 \%$ of fractures occurred in tusks that were less than or equal to $1 \mathrm{ft}$, with the other $25 \%$ occurring in tusks greater than $1 \mathrm{ft}$ in length.

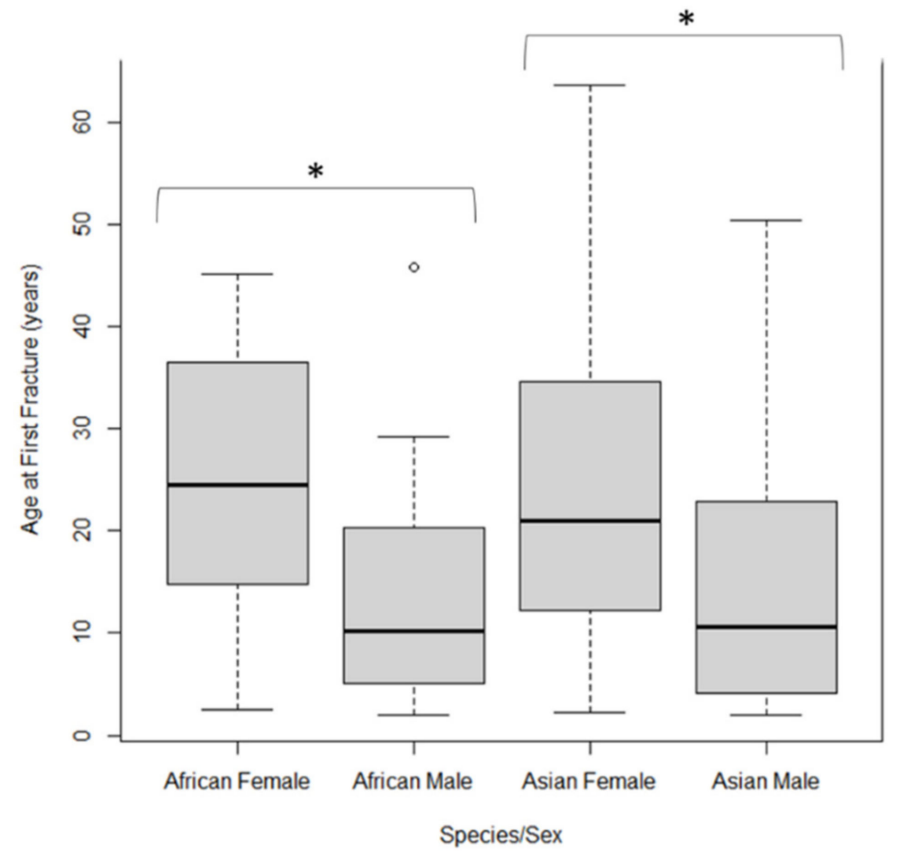

Figure 1. Age (years) at first tusk fracture by species and sex. Asterisk $\left(^{*}\right)$ note values of pairings are significantly different.

\subsection{Existing Tusk Pathology and Endodontics Present at the Time of Fractures}

Pre-existing conditions and treatments including pericoronitis, abrasions/wear, pulp exposure prior to fracture, supernumerary tusks, and presence of acrylic/Kevlar caps and metal crown/caps were infrequently associated with fractures, occurring in less than $9 \%$ of all fractures each. Tushes were reported as present in only Asian females, with 63.6\% of fractures occurring in tush tusks. Previous endodontic repairs were more frequently associated with repeated fractures, having occurred in $19.4 \%$ of prior tusk fractures in this study period. For African elephants, there was a significant association between sex and previous repairs $\left(\chi^{2}=8.677, \mathrm{df}=1, p=0.003\right)$. Odds ratio calculations showed that African males were 6.20 times more likely to fracture a previously repaired tusk than African females. No significant association was found between Asian males and Asian females $\left(x^{2}=0.832, \mathrm{df}=1, p=0.362\right)$, with an odds ratio showing males were 1.96 times more likely to fracture an endodontically repaired tusk than females.

Twenty-eight elephants were reported to sustain multiple fractures (African, 5.8; Asian, 5.10). Odds ratios showed that species/sex groupings were approximately equal in their chance of sustaining multiple fractures in the study period (ORAfrican $=1.01$; ORAsian $=1.05$ ). Of these individuals, 13 fractured the same tusk at least twice (African $=3.6$, Asian $=2.2$ ). Odds ratios showed that African females were 1.29 times more likely to fracture the same tusk at least twice than African males, and Asian males were 2.16 times more likely to fracture the same tusk at least twice than Asian females. Of these multiple fractures to the same tusk, $78.9 \%$ were fractured twice during the study period. The remaining were fractured more than twice (range: $3-5$ ). The average number of days between fractures of 
the same tusk was $1232.12(\mathrm{SE}=199.23)$. The average number of days between a first and second fracture of the same tusk was $1277.42(\mathrm{Mdn}=987, \mathrm{SE}=239.88)$, and the average number of days between subsequent fractures (i.e., second to third, third to fourth, etc.) was $1088.67(\mathrm{Mdn}=1118, \mathrm{SE}=328.03)$.

\subsection{Circumstances Surrounding Fractures}

Tusk fractures had unknown causes in $36.2 \%$ of cases. Of fractures with known causes, $44.6 \%$ occurred during conspecific interactions, $28.4 \%$ occurred from tusks being caught in an enclosure or enrichment item, $12.2 \%$ occurred following striking or making contact between the tusk and an item in their space, $6.8 \%$ occurred following a fall or slip, $5.4 \%$ occurred from chronic wear of tusks and $2.7 \%$ occurred in "other" categories. "Other" was used to capture and group less frequent events, of which two were described. One fracture was related to an underlying medical condition, and one occurred during a medical procedure. Some variation was observed in the cause of fractures within species/sex groupings. Odds ratios were calculated for all species/sex comparisons to describe these differences. Asian males were 13.93 times more likely than Asian females to fracture a tusk via enclosure or enrichment entrapment. Asian females were 5.22 times more likely to fracture a tusk via striking or making contact with an item in their environment than Asian males. Similarly, African females were 2.00 times more likely to fracture a tusk via striking or making contact with an item in their environment than African males. African males were 3.07 times more likely than African females to fracture a tusk subsequent to chronic wear or rubbing. All other odds ratios were of values less than 2 (Figure 2).

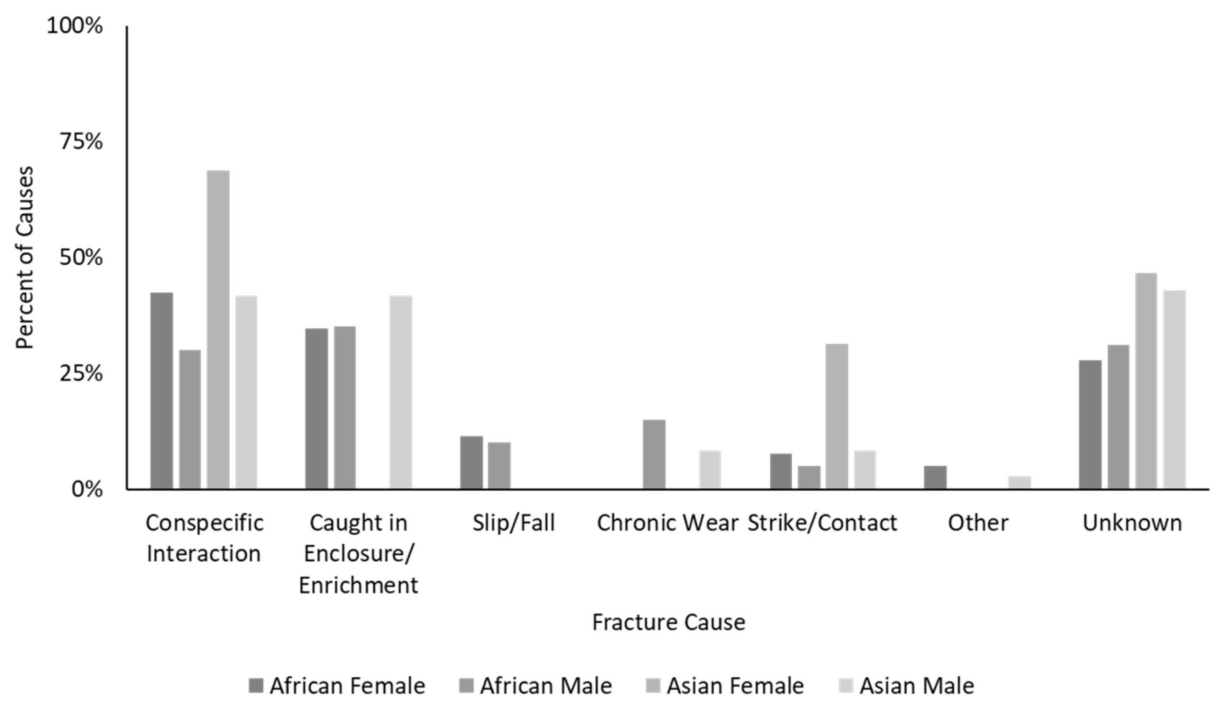

Figure 2. Percent of causes of tusk fractures by species/gender grouping. Unknown causes are calculated as a percent of all fractures. Known causes are calculated as a percent of all fractures with known cause.

\subsection{Housing Factors}

Where tusk fractures occurred within an institution varied as some institutions had more complex facilities. For applicability, data were summarized as occurring in indoor or outdoor spaces. For fractures with a known occurrence location, 59.8\% occurred in an indoor space. Except for Asian males, who had more fractures occur outdoors (53.3\%), all species/sex groupings had fractures occur more frequently indoors (African female, $64.3 \%$; African male, $52.4 \%$; Asian female, $72.7 \%$ ). Though some variation was observed, no significant association was found between species/sex grouping and location of fractures (African, $\chi^{2}=0.704, \mathrm{df}=1, p=0.401$; Asian, $\chi^{2}=1.993$, $\mathrm{df}=1, p=0.158$ ). Grouping indoor and outdoor incidence, steel gates were associated with $23.8 \%$ of fractures caused by exhibit elements (3.7\% of all fractures). Other exhibit elements, including concrete walls, bollards, hotwire, and metal " $\mathrm{D}$ " rings, were associated with either a singular incidence 
or no incidence of fractures. The types of substrates the elephants were on at the time of fracture were also recorded, in addition to the fracture's location within the enclosure. Only two tusk fractures (1.5\% of all) cited the ground as a contributory factor, both of which occurred on concrete. Four fractures $(2.9 \%)$ were associated with feeding, which included ground feeding and elevated feeding opportunities for the elephants. One fracture occurred during a training session with a keeper, but no other fractures were associated with human-driven interactions.

\subsection{Behavioral/Social Factors}

Socially, $2.9 \%$ of fractures occurred in a newly introduced individual, $25.4 \%$ occurred in the established dominant herd member, and $22.4 \%$ occurred in the most subordinate herd member. For males, $22.8 \%$ of fractures occurred while experiencing musth. For females, $17.1 \%$ of fractures occurred while in estrus. For fractures involving conspecifics, details were provided for $33 \%$ of cases in which unstable hierarchy $(45.5 \%)$ and specific agonistic interactions (36.4\%) were the most frequently cited causes. Fractures coincided with at least one male at the facility being in musth in $14.2 \%$ of cases and $67.2 \%$ of cases occurred in herds with cycling females. In $13.4 \%$ of all fractures, the elephant had no direct physical access to other elephants; $22.2 \%$ of these occurred in females and $77.8 \%$ occurred in males.

\subsection{Interventions Attempted to Mitigate Future Fractures}

Following fractures, no changes to management occurred in $40.7 \%$ of cases. When management changes were made, they included more frequent/targeted tusk trims (49.3\%), modifications to enclosure or enrichment programs (21.9\%), modifications to social group arrangements (15.1\%), and implementation of behavior modification/redirection plans (13.7\%). Adding protective crowns in the absence of other pathology was not reported. Combining all management changes and species/sex groupings, there was a significant association between management changes following a tusk fracture and the occurrence of a second fracture on the same tusk $\left(\chi^{2}=12.562, \mathrm{df}=1, p<0.001\right)$. Odds ratios showed that a second tusk fracture was 6.37 times more likely to occur if no management changes were instituted following the first reported tusk fracture.

\section{Discussion}

This study accomplished the most detailed and inclusive data set of factors implicated in the development of elephant tusk fractures under managed care to date. Data analysis aligns with prior findings in that the prevalence of traumatic tusk fractures in zoos is generally higher than for in situ populations. The surveyed population had a prevalence of $18.5 \%$ (incidence of 134 tusk fractures affecting 85 animals in a population of 459 animals), lower than the prevalence of 31\% (incidence of 234 tusk fractures affecting 118 animals in a population of 380 animals) reported by McCullar et al. in 1994 [13]. Neither data set specifically accounts for "tusklessness" which can be either acquired or genetic [17], and is common in Asian elephant cows [13]. This lower number might suggest that the tusk fracture incidence has truly decreased since 1994, perhaps because of evolution in elephant management and enclosure design. Another reason for the discrepancy could be that this study was limited to fractures over a twelve-year period (2009-2021), while the earlier report captured any recorded fracture occurring in the North American elephant populations over an 86-year period (1908-1994). The actual prevalence of any condition is more likely to be captured in a longer study period for a long-lived animal like elephants. However, the primary goal of this study was to reflect current management practices as they relate to tusk fracture development, rather than calculating true prevalence of this condition in the entire managed elephant population. Further, the present study's prevalence included zoos across five continents, while the previous report was limited to North American zoos. Geographic location was not accounted for as a variable for fracture development within this study but is an area for future investigation, especially as it relates to indoor and outdoor exhibit use. The median in situ tusk fracture incidence of $1.31 \%$ 
described across all tusks in 15 populations of African savanna elephants [17] is lower than either our or McCullar et al.'s data set. This wild elephant data set was generated through evaluation of digital images, calculating the incidence of fractures in observed tusks instead of the prevalence of fractures in an elephant population. Calculated prevalence is generally higher than calculated incidence. However, there is a notable discrepancy between the in and ex situ populations. This suggests that tusk fractures occur more frequently in managed care, meriting further investigation.

First, the circumstances surrounding fractures identified trends as to why tusk fractures occur more frequently in managed care. Conspecific interactions, striking/making contact between a tusk and an item in the elephant's enclosure, and entrapment in an enclosure or enrichment item accounted for $85.2 \%$ of known causes of fractures. Of these causes, conspecific interactions were cited the most frequently. The term 'conspecific interaction' was intentionally kept vague within the survey as to whether the interaction was agonistic or affiliative to improve the objectivity of the data. However, the available supplemental data for conspecific mediated fracture events implicated unstable hierarchy and specific agonistic interactions in $81.9 \%$ of fractures, supporting that these were likely agonistic events. Almost half of the tusk fractures (47.8\%) occurred in individuals that were either the established dominant or most subordinate member of the herd. Assuming an average herd size of 9.18 within the study population, approximately $21.8 \%$ of individuals would be an established dominant or subordinate, implying that these individuals are overrepresented to go on to develop tusk fractures. Agonistic behaviors establish and reinforce dominance status, which is essential for maintaining harmony and avoiding escalation to aggression [21,22]. The complex social structure of elephants can differ in managed care compared to free-ranging populations. Managed elephant herds have wider ranges of group sizes, more varied age structures and degrees of relatedness than wild counterparts [22] and may include both African and Asian species [23]. These factors have a significant influence on social behavior. Our data suggests that an increase in agonistic events in managed care is a significant cause of tusk fractures and should be considered in tusk health management plans.

Interestingly, this finding aligns with certain conditions in wild African savannah elephants. The highest reported incidence of fractures reported in situ $(44.4 \%)$ has been reported in Etosha National Park in Namibia. This location is one of the driest climates inhabited by African elephants [17]. Though elephant ivory can become brittle when stored in low humidity, this finding has not been confirmed in living individuals [12]. Another theory for the uniquely high incidence of tusk fractures in this region is that there are larger aggregations of elephants at the relatively sparse permanent water locations compared to wetter regions, precipitating more hostile social interactions [17]. Our data again lends support to this theory as it broadly demonstrated fractures to occur more frequently indoors compared to outdoors. Though the specific dimensions of indoor and outdoor exhibits were not requested, the surface area of indoor housing is generally smaller than outdoor yards. Like the higher density of wild elephants at limited water locations, a higher density of elephants indoors may lead to increased chances of a conspecific and/or exhibit-mediated fracture events.

Reproductive status has a significant impact on social interactions among elephants [19,24]. Males developed their first tusk fracture approximately a decade younger than females in both species (Figure 1). This age corresponds with reported ages of onset of musth in managed Asian and African males of 14.5 years old [25] and 13-18 years old [26], respectively. Over a fifth of the fractures in males occurred when they were in musth. The amount of time managed male elephants spend in musth is highly variable but is associated with high levels of androgens and aggression [26]. Both African and Asian bulls display similar presentations [27]. Though it has been described that tusks can be used in social interactions and as weapons [13], closer investigation has demonstrated that tusk size has little correlation with male-to-male conflict outcomes in wild Asian elephants [19]. In most tactile contests in wild Asian bulls, high-impact head-butting 
and wrestling were more common than 'fencing' or goring with tusks [19]. Tusks were more likely to be broken because of an agonistic conflict than to serve an advantage as a direct sparring weapon [19]. While large tusks can be an effective display of physical fitness to cows [28], their effectiveness as weapons is limited because they break easily in comparison to the strength of an elephant [19]. A majority (77.8\%) of the fractures that occurred in individually housed elephants were in males. This may reflect that males are more commonly housed in isolation than females for various management reasons, or that they are housed in isolation while in musth and are more likely to incur a tusk fracture as a result of their increased aggression. Based on observations of wild African elephants, the latter is a feasible explanation. Wild bulls spend most of their time in association with other males in a non-musth state, while during musth they spend most of their time with females [27]. Thus, housing a bull in musth in isolation out of management necessity when the bull's drive is to be with females could precipitate a situation where a tusk fracture could develop.

This study's data additionally illustrates a more pronounced association between gender and the development of tusk fractures than McCullar et al., with males more represented than females. Similarly, free ranging African savannah bulls have a higher reported incidence of tusk fractures than females [17]. This finding was anticipated between Asian males and females due to the marked discrepancy in size and/or complete absence of tusks in Asian cows. However, African bulls were also more likely to sustain tusk fractures than African cows, albeit to a lesser degree. The reason for this gender discrepancy is not fully described in the data set but may be related to the younger average age of first tusk fracture in males compared to females in both Asian and African elephants. Both African and Asian bulls in managed care experience musth nearly a decade sooner (from ages 13-18 years) than their wild counterparts ( $\geq 25$ years old) [25-27]. Musth may be suppressed in less dominant African males by the presence of more dominant bulls in the wild [29], but no significant correlation has been noted between dominance status and onset of musth in bulls under managed care [30]. At an average age of 14 years, African males in situ are only beginning the process of seeking independence from their matriarchal family unit [29]. They do not successfully compete for females in estrous until they are 30 years old [29]. In summary, managed bulls will have spent more time in a state of increased aggression with a high frequency of "tusking" behaviors with inanimate objects [27] compared to wild counterparts.

Estrus and estrous cycles may have similarly impacted the frequency of conspecific interactions resulting in tusk fractures. Though a cohort of cycling versus non-cycling females and their respective incidences of tusk fractures was not compared, $67.2 \%$ of conspecific interactions leading to fractures occurred in institutions with at least one female with active estrous cycles in the 12-year study period, and almost a fifth (17.1\%) of fractures occurred when a female in the herd was in estrus. Bioactive compounds secreted by elephants transmit information about an individual's reproductive status and dominance within the herd [31]. Studies have shown that these signals lead to the cycling female receiving fewer aggressive contacts but, conversely, delivering more aggressive contacts. Rates of aggression are even higher if the cycling female is a larger, dominant member of the herd [32]. This further aligns with our finding of dominant animals developing more tusk fractures than mid-ranking herd members. These findings additionally support that unstable herd dynamics can precipitate events resulting in tusk fractures.

In addition to conspecific interactions, striking of enclosure elements was another commonly implicated circumstance surrounding tusk fractures. A weakness in the data set is that striking an enclosure element could be indirectly related to a conspecific interaction. The authors have observed elephants to redirect their frustration from a social situation to an inanimate object with enough force to break a tusk. However, the motivation for why an elephant would strike an object can be subjective. There is evidence that the presence of a previous endodontic repair is associated with increased risk of repeated tusk fractures. This is particularly noted in African bulls. It is possible the increased risk of repeated fracture 
could be related to a change in the tusk that might encourage an elephant to fixate on it (ex: the tusk is a different weight, there is a metal tusk cap present, etc.) and strike an enclosure element. Additionally, fractures that undergo endodontic repair are typically more severe, suggesting the tusks may be compromised and prone to chronic inflammatory processes which may cause discomfort. Other pre-existing tusk pathologies were not significantly noted in association with fracture development.

Finally, entrapment of a tusk in an enclosure or enrichment item was an important cause for fracture development. The description "entrapment" implies an accidental event and targets improvements that may be made surrounding exhibit elements. Safely housing elephants under managed care necessitates the use of strong building materials. Concrete floors, cement barriers, and metal bars may all present risks for falls, tusk wear, and tusk breakage [18]. Of the tusk fractures in our study, 50.7\% reported some involvement of an exhibit element (when combining fractures that occurred because of both striking and entrapment); however, only $12.6 \%$ of the fractures had information about which specific housing element was involved. Steel gates were most implicated. Treating these surfaces with a bonded polyurethane/polyurea liner may absorb some of the impact of a tusk strike and reduce chronic wear in elephants prone to tusk damage but has not been tested. However, elephants can be persistent in their attempts to remove coatings, and this could draw more attention to the gates [33]. Our data further supports that fractures can occasionally involve cement flooring, which suggests that the use of softer substrates like dirt, sand or rubberized matting could help prevent some fractures [18].

While conspecific interactions and striking or entrapment of enclosure elements were important factors within the data set, several of the evaluated factors were not strongly implicated in the development of tusk fractures. First, tusk length was hypothesized to be a significant factor because the length of a linear object negatively affects tensile strength [34] and has been suggested previously [13]. However, many of the tusks fractured in both Asian and African elephants were less than a foot in length. This may reflect that tusks in managed care are shorter due to either routine tusk trimming, wear on enclosures and/or a higher incidence of tusk fractures. However, there are managed elephants known to have tusks greater than $2 \mathrm{~m}$ in length [35], further suggesting that other factors beyond tusk length are important in tusk fracture development. Another finding was the high incidence of fractures in Asian elephant females" "vestigial tusks" or "tushes" [13]. The use of the term "tushes" is often unclear [18]. It has been proposed to exclusively use the term to describe the deciduous tusks that are replaced after an elephant reaches 1 year of age $[18,36]$, but the term has been used to refer to the shorter tusks noted in Asian elephant females [18]. No deciduous tusks were reflected in the data set, as the only tushes reported were in adult Asian females. Incidentally, fractures in these short Asian cow tusks were less likely to be of clinical significance, perhaps because they possess shorter pulps. No Asian cows were reported to have required endodontic treatment for a tusk fracture in the data set. Second, it was hypothesized that there would be individuals that would be overrepresented within the study population, suggesting an inherent "individual predisposition" towards fracturing tusks. This was not strongly supported within the data. Of elephants who fractured their tusk(s), approximately 15\% fractured the same tusk at least one additional time in the study period. For these elephants, the time between fractures of the same tusk was, on average, 3.4 years. The relatively long duration between tusk fractures in individuals suggests that these fractures are typically isolated events and certain individuals are not more prone than others to go on to develop fractures. Third, it was hypothesized that there would be an association between molar disease and tusk fractures, which was not illustrated within the data set. The lack of evidence that these three factors were implicated underlines the importance of conspecific interactions and exhibit elements in tusk fracture development.

There were several factors that were beyond the scope of this investigation. As mentioned previously, geographic location was not investigated as this would have subdivided the data set too heavily. Genetics and diet, particularly as they may relate to tusk tensile 
strength, were further beyond the scope of the study. However, based on previous evidence [37], variation in tusk composition exists with geography and diet and these factors are worthy of further study.

Lastly, the most encouraging finding within the data set was the efficacy of intervention strategies to mitigate the development of future fractures. Tusk trimming, or the process of proactively shortening tusk length, was the most employed intervention. This practice is thought to reduce fracture development by reducing length and therefore improving tensile strength. A strategy of trimming the elephant's preferred tusk for object manipulation [38] to a length shorter than the contralateral tusk has been employed successfully by elephant managers [33]. Though there was previously a lack of evidence for efficacy for these practices [18], this finding suggests that trimming may be effective in reducing the risk of future tusk fractures. However, great care should be taken with tusk trimming as there is no validated method to predict the location of the pulp [18], and pulp exposure is undesirable. The authors strongly encourage taking tusk radiographs prior to trimming to help avoid pulp exposure. While enclosure modifications, enrichment programs, modifications to social groupings, and behavioral redirection plans were all reported as interventions, the study's findings suggest that there is an opportunity for growth in these areas to reduce the incidence of tusk fractures. Though tusk trimming accounted for almost half of the interventions, conspecific interactions are a more significant factor in fracture development in comparison to tusk length. Strategies to reduce tusk fractures should be targeted towards reducing tusk-damaging behaviors and encouraging positive conspecific interactions. Ample space and resource distribution allow more opportunity for an elephant to avoid engaging with a herd mate, as well as meeting the need for enough space and resources to support evolving herd dynamics [21]. Provision of appropriate social structure and ample behavioral and environmental enrichment may prevent the occurrence of conflict and stereotypical behaviors amongst herd members [23] and potentially reduce the incidence of unfavorable interactions. This study's findings support previous conclusions that improved welfare benefits the overall health of the individual elephant [39]. As elephant management continues to evolve [21], revisiting this survey model in the upcoming decade has the potential to elucidate the true impact of these management practices on reducing the incidence of tusk fractures in managed elephants globally.

\section{Conclusions}

Conspecific interactions and entrapping or striking tusks on enclosure elements are the most frequently identified direct circumstances surrounding elephant tusk fractures in managed care. Unstable herd dynamics and antagonistic interactions are frequently implicated, and adolescent males are overrepresented. Mitigation strategies in the form of tusk trimming, enrichment, and social or enclosure modifications, are effective in reducing the frequency of tusk fractures in managed care.

Supplementary Materials: The following supporting information can be downloaded at: https: / / www.mdpi.com/article/10.3390/jzbg3010008/s1, File S1: Tusk fracture epidemiology survey.

Author Contributions: Conceptualization, J.B.R., J.S.P., J.O. and D.A.F.; methodology, J.B.R. and A.L.; software, J.B.R.; formal analysis, A.L.; investigation, J.B.R., A.L., R.L. and L.M.Y.; resources, D.A.F.; data curation, J.B.R., R.L. and L.M.Y.; writing-original draft preparation, J.B.R., M.A.F., R.L. and L.M.Y.; writing - review and editing, A.W., A.L., M.A.F. and M.R.B.; visualization, A.L.; project administration, J.B.R. All authors have read and agreed to the published version of the manuscript.

Funding: This research received no external funding.

Institutional Review Board Statement: Not applicable.

Data Availability Statement: Data is available for further review by contacting the primary author, J.B.R., and would involve receiving the authorization of the participating institutions (see "Acknowledgements"). 


\begin{abstract}
Acknowledgments: The authors would like to acknowledge the efforts of Yurie Yamada, BVSc, in her translation of the surveys into the Japanese language, in addition to Waka Otozu, JAZA Asian elephant studbook keeper. Their combined efforts facilitated the inclusion of JAZA within the study. In addition, Willem Schaftenaar, D., provided valuable feedback in the development of the surveys and aided the efforts for endorsement by EAZA. Alan Roocroft provided support in the inclusion of institutions in Asia, Australia and Europe. Steve LeFave further gave insight into elephant tusk fracture management strategies. The EAZA Elephant Taxon Advisory Group gave essential critique in the development of the research study design. We additionally acknowledge the participation of the following institutions without whom the completion of this project would not have been possible: Africam Safari Park, Asa Zoo, Beauval Zoo, Birmingham Zoo, Caldwell Zoo, Chester Zoo, Columbus Zoo and Aquarium, Copenhagen Zoo, Denver Zoo, Der grune Zoo Wuppertal, Disney's Animal Kingdom, Fresno Chaffee Zoo, Fundación Botánica y Zoológica de Barranquilla, Grant's Farm, Hirakawa Zoological Park, Hitachi City Kamine Zoological Park, Indianapolis Zoological Society, Knie's Kinderzoo, Little Rock Zoo, Los Angeles Zoo and Botanical Gardens, Maryland Zoo in Baltimore, Milwaukee County Zoological Gardens, Montgomery Zoo, Nagano Chausuyama Zoo, Naturaleza de Cabarceno Park, Noah's Ark Zoo Farm, North Carolina Zoological Park, Oakland Zoo, Okinawa Zoo and Museum, Oklahoma City Zoo and Botanical Gardens, Ouwehands Dierenpark, Pairi Daiza, Parc zoologique de Plaisance du Touch, Pittsburgh Zoo and PPG Aquarium, Prague Zoo, Reid Park Zoo, Réserve Africaine de Sigean, Rosamond Gifford Zoo at Burnet Park, Rotterdam Zoo, San Diego Zoo Wildlife Alliance, Santa Barbara Zoological Gardens, Sapporo Maruyama Zoo, Sedgewick County Zoo, Smithsonian National Zoological Park, Taronga Zoo, Terra Natura, The Elephant Sanctuary, Thoiry Zoo Safari, Tierpark Berlin, Tokyo Tama Zoological Park, Toyohashi Zoological and Botanical Park, Ueno Zoological Gardens, West Midland Safari Park, Wild Animal Park Mechelen Planckendael, Zoo Basel, and Zoological de Zacango.
\end{abstract}

Conflicts of Interest: The authors declare no conflict of interest.

\title{
References
}

1. Loxodonta africana. The IUCN Red List of Threatened Species. Available online: http:/ / dx.doi.org/10.2305/IUCN.UK.2008.RLTS. T12392A3339343.en (accessed on 15 November 2021).

2. Elephas maximus. The IUCN Red List of Threatened Species 2020. Available online: https://dx.doi.org/10.2305/IUCN.UK.2020-3 .RLTS.T7140A45818198.en (accessed on 15 November 2021).

3. Miller, M.A.; Hogan, J.N.; Meehan, C.L. Housing and Demographic Risk Factors Impacting Foot and Musculoskeletal Health in African Elephants [Loxodonta africana] and Asian elephants [Elephas maximus] in North American Zoos. PLoS ONE 2016, 11, e0155223. [CrossRef]

4. Holdgate, M.R.; Meehan, C.L.; Hogan, J.N.; Miller, L.J.; Soltis, J.; Andrews, J.; Shepherdson, D.J. Walking Behavior of Zoo elephants: Associations between GPS-Measured Daily Walking Distances and Environmental Factors, Social Factors, and Welfare Indicators. PLoS ONE 2016, 11, e0150331. [CrossRef]

5. Morfeld, K.A.; Brown, J.L. Metabolic Health Assessment of Zoo Elephants: Management Factors Predicting Leptin Levels and the Glucose-to-Insulin Ratio and Their Associations with Health Parameters. PLoS ONE 2017, 12, e0188701. [CrossRef] [PubMed]

6. Brown, J.L.; Paris, S.; Prado-Oviedo, N.A.; Meehan, C.L.; Hogan, J.N.; Morfeld, K.A.; Carlstead, K. Reproductive Health Assessment of Female Elephants in NORTH American Zoos and Association of Husbandry Practices with Reproductive Dysfunction in African Elephants (Loxodonta africana). PLoS ONE 2016, 11, e0145673. [CrossRef] [PubMed]

7. Espinoza, E.O.N.; Mann, M.J. The history and significance of the Schreger pattern in proboscidean ivory characterization. J. Am. Inst. Conserv. 1993, 32, 241-248. [CrossRef]

8. Miller, W.D. Studies on the anatomy and pathology of the tusks of the elephant. Dent. Cosm. 1890, 32, 337-348.

9. Miles, A.E.W.; White, J.W. Ivory. J. R. Soc. Med. 1960, 53, 775-780. [CrossRef]

10. Shoshani, J. General information on elephants with emphasis on tusks. Elephant 1978, 1, 11. [CrossRef]

11. Sperber, G.H. Tusks. Dent. J. 1976, 42, 257-268.

12. Rajaram, A. Tensile properties and fracture of ivory. J. Mater. Sci. Lett. 1986, 5, 1077-1080. [CrossRef]

13. McCullar, M.; Mikota, S.K.; Sargent, E.L.; Ranglack, G.S. Dentistry. In Medical Management of the Elephant; Mikota, S.K., Sargent, E.L., Ranglack, G.S., Eds.; Indira Publishing: West Bloomfield, MI, USA, 1994; pp. 87-94.

14. McGavin, M.D.; Walker, R.D.; Schroeder, E.C.; Patton, C.S.; McCracken, M.D. Death of an African elephant from probable toxemia attributed to chronic pulpitis. J. Am. Vet. Med. Assoc. 1983, 183, 1269-1273. [PubMed]

15. Sim, R.R.; Stringer, E.; Donovan, D.; Chappell, R.; Flora, P.; Hall, J.; Pillay, S.; Willis, B.G.; McCain, S. Use of Composite Materials As a Component of Tusk Fracture Management in an Asian Elephant (Elephas maximus) and an African Elephant (Loxodonta africana). J. Zoo Wildl. Med. 2017, 48, 891-896. [CrossRef] [PubMed]

16. Shoshani, S.L. Captive elephant population in the world: 1988-1999, and notes on other captive elephants elsewhere in the world. Elephant 2000, 2, 20. [CrossRef] 
17. Steenkamp, G.; Ferreira, S.M.; Bester, M.N. Tusklessness and Tusk Fractures in Free-Ranging African Savanna Elephants (Loxodonta africana). J. S. Afr. Vet. Assoc. 2007, 78, 75-80. Available online: https://hdl.handle.net/10520/EJC99714 (accessed on 15 November 2021). [CrossRef]

18. Steenkamp, G. Management of Dental Disease in Elephants. In Fowler's Zoo and Wild Animal Medicine; Miller, R.E., Lamberski, N., Calle, P., Eds.; Elsevier: St. Louis, MO, USA, 2019; Volume 9, pp. 657-664.

19. Chelliah, K.; Sukumar, R. The role of tusks, musth and body size in male-male competition among Asian elephants, Elephas maximus. Anim. Behav. 2013, 86, 1207-1214. [CrossRef]

20. Terms of Use, Momentive, Inc. Available online: https://www.surveymonkey.com/mp/legal/terms-of-use/ (accessed on 16 August 2021).

21. Glaeser, S.S.; Shepherdson, D.; Lewis, K.; Prado, N.; Brown, J.L.; Lee, B.; Wielebnowski, N. Supporting Zoo Asian Elephant (Elephas maximus) Welfare and Herd Dynamics with a More Complex and Expanded Habitat. Animals 2021, 11, 2566. [CrossRef] [PubMed]

22. Schulte, B.A. Social Structure and Helping Behavior in Captive Elephants. Zoo Biol. 2000, 19, 447-459. [CrossRef]

23. Fowler, M.; Mikota, S.K. (Eds.) Biology, Medicine, and Surgery of Elephants; John Wiley \& Sons: Hoboken, NJ, USA, 2006.

24. Freeman, E.W.; Weiss, E.; Brown, J.L. Examination of the interrelationships of behavior, dominance status, and ovarian activity in captive Asian and African elephants. Zoo Biol. 2004, 23, 431-448. [CrossRef]

25. Taylor, V.J.; Poole, T.B. Captive breeding and infant mortality in Asian elephants: A comparison between twenty western zoos and three eastern elephant centers. Zoo Biol. 1998, 17, 311-332. [CrossRef]

26. Ganswindt, A.; Heistermann, M.; Hodges, K. Physical, physiological, and behavioral correlates of musth in captive African elephants (Loxodonta africana). Physiol. Biochem. Zool. 2005, 78, 505-514. [CrossRef]

27. Poole, J.H. Rutting behavior in African elephants: The phenomenon of musth. Behaviour 1987, 102, 283-316. [CrossRef]

28. Watve, M.G.; Sukumar, R. Asian elephants with longer tusks have lower parasite loads. Curr. Sci. 1997, 72, 885-889. Available online: https: / / www.jstor.org/stable/24100035 (accessed on 16 August 2021).

29. Poole, J.H. Musth and Male-Male Competition in the African Elephant. Doctoral Dissertation, University of Cambridge, Cambridge, UK, 1982.

30. Scott, N.L.; Riddle, H. Assessment of musth in captivity: A survey of factors affecting the frequency and duration of musth in captive male elephants Elephas maximus and Loxodonta africana. J. Elephant Manag. 2003, 13, 11-15.

31. Rasmussen, L.E.L.; Krishnamurthy, V. How chemical signals integrate Asian elephant society: The known and the unknown. Zoo Biol. 2000, 19, 405-423. [CrossRef]

32. Slade-Cain, B.E.; Rasmussen, L.E.L.; Schulte, B.A. Estrous state influences on investigative, aggressive, and tail flicking behavior in captive female Asian elephants. Zoo Biol. 2008, 27, 167-180. [CrossRef]

33. Lefave, S.; (Oregon Zoo, Portland, OR, USA). Personal communication, 2012.

34. Showalter, K.L. Effect of Length on Tensile Strength in Structural Lumber; US Department of Agriculture, Forest Service, Forest Products Laboratory: Madison, WI, USA, 1987; Volume 482.

35. Bon, Asian Elephant (Elephas maximus) Located at Yokohama Kanazawa Zoo in Japan. Elephant Encyclopedia. Available online: https:/ / www.elephant.se/database2.php?elephant_id=5770 (accessed on 27 December 2021).

36. Raubenheimer, E.J.; Van Heerden, W.F.P.; Van Niekerk, P.J.; De Vos, V.; Turner, M.J. Morphology of the deciduous tusk (tush) of the African elephant (Loxodonta africana). Arch. Oral Biol. 1995, 40, 571-576. [CrossRef]

37. Raubenheimer, E.J.; Brown, J.M.M.; Rama, D.B.K.; Dreyer, M.J.; Smith, P.D.; Dauth, J. Geographic variations in the composition of ivory of the African elephant (Loxodonta africana). Arch. Oral Biol. 1998, 43, 641-647. [CrossRef]

38. Bielert, C.; Costo, N.; Gallup, A. Tuskedness in African elephants-an anatomical investigation of laterality. J. Zool. 2018, 304, 169-174. [CrossRef]

39. Brown, J.L.; Bansiddhi, P.; Khonmee, J.; Thitaram, C. Commonalities in management and husbandry factors important for health and welfare of captive elephants in North America and Thailand. Animals 2020, 10, 737. [CrossRef] 